\title{
Negosiasi Performativitas Pedagogis Pembelajaran musik Generasi Z
}

\author{
Imam Bahaudin ${ }^{1}$, Anik Juwariyah ${ }^{2}$, Setyo Yanuartuti ${ }^{3}$ \\ Pendidikan Seni Budaya, Pascasarjana Universitas Negeri Surabaya \\ e-mail: imambahaudin@ymail.com
}

\begin{abstract}
This study identifies and explores the negotiations that occur as pedagogical performativity in learning music in the digital era for Generation Z. This study also looks at the performativity of conventional to modern music learning. Furthermore, it can be known and clarified the position of music learning and its flexibility in learning modern music for generation Z. This type of research is qualitative with a case study approach. Data were obtained with questionnaires in qualitative research, and interviews, which were taken from April 2020 to January 2021. The data sources were 100 music teachers in Surabaya and Sidoarjo, East Java. The research point of view uses the concept of children's musical aspects popularized by Schu-Fang Lin and Helena Gaunt (2016) about the pedagogy of 21st Century music learning. The results show that performativity and pedagogical negotiation in Generation $\mathrm{Z}$ music learning begins with awareness and learning innovations carried out by teachers. The teacher realizes that the entry of technology has a significant role in the learning process of music. Negotiation of performativity and pedagogy ultimately leads to a multidimensional learning model that has a reciprocal effect on students. Multidimensional learning highlights the advantages of embracing technology for music learning for Generation $\mathrm{Z}$ without obscuring the traditional and other essential aspects of music and conventional learning. The use of technology and the negotiations that occur in it raises multidimensional learning, which aims to include aspects of the face-to-face classroom learning experience with technology-based learning experiences to become an attraction for Generation $\mathrm{Z}$ in music learning.
\end{abstract}

Keywords: negotiating, performativity, pedagogy, music learning, Generation Z

\begin{abstract}
Abstrak: Penelitian ini mengidentifikasi dan mengeksplorasi tentang negosiasi yang terjadi sebagai performativitas pedagogis dalam pembelajaran musik dalam era digital bagi Generasi Z. Penelitian ini turut melihat performativitas dari pembelajaran musik secara konvensional ke modern. Lebih lanjut, dapat diketahui dan memperjelas terkait posisi pembelajaran musik dan fleksibilitasnya dalam pembelajaran musik secara modern bagi generasi Z. Jenis penelitian ini adalah kualitatif dengan pendekatan studi kasus. Data diperoleh dengan bantuan kuesioner dalam penelitian kualitatif, dan wawancara, yang diambil pada April 2020 hingga Januari 2021. Sumber data adalah 100 guru musik yang berada di Surabaya dan Sidoarjo, Jawa Timur. Sudut pandang penelitian menggunakan konsep tentang aspek musikal anak-anak yang dipopulerkan oleh Schu-Fang Lin, dan dari Helena Gaunt (2016) tentang pedagogis pembelajaran musik Abad 21. Hasil penelitian menunjukkan bahwa negosiasi perfromativitas dan pedagogis dalam pembelajaran musik Generasi $\mathrm{Z}$ diawali dari kesadaran dan inovasi pembelajaran yang dilakukan oleh guru. Guru menyadari masuknya teknologi memiliki andil yang signifikan dalam proses pembelajaran musik. Negosiasi performativitas dan pedagogis pada akhirnya menuju pada model pembelajaran multidimensi yang memberikan efek timbal balik bagi peserta didik. Pembelajaran multidimensi menyoroti keuntungan dalam merangkul teknologi untuk pembelajaran musik bagi Generasi $\mathrm{Z}$ tanpa mengaburkan aspek tradisi dan aspek penting lain dalam musik dan juga pembelajaran konvensional. Pemanfaatan teknologi dan negosiasi yang terjadi di dalamnya memunculkan ide tentang pembelajaran multidimensi yang bertujuan untuk memasukkan aspek-aspek dari pengalaman pembelajaran kelas tatap muka dengan pengalaman pembelajaran berbasis teknologi untuk menjadi daya tarik bagi Generasi Z dalam pembelajaran musik.
\end{abstract}

Kata Kunci: Negosiasi, performativitas, pedagogis, pembelajaran musik, Generasi Z

\section{Article info:}

Received: 15 Februari 2021

Reviewed: 04 April 2021

Accepted:26 Juni 2021 


\section{PENDAHULUAN}

Pembelajaran musik dan lanskap sekitarnya bagi anak-anak dan masyarakat terus berubah. Pembelajaran musik saat ini pada hakekatnya selaras dengan pertunjukan musik di mana telah mengalami pergeseran dari ruang konser ke rekaman fisik dan sekarang ke arena digital (Cayari, 2018; King et al., 2019). Ketika disubtitusikan ke dalam pembelajaran musik, maka pergeseran terjadi dari ruang keterampilan ke ruang pendidikan formal dan sekarang ke ruang pendidikan digital (Cayari, 2018; Waldron et al., 2018). Evolusi ini terkait dengan historiografi yang menunjukkan bahwa sebelum abad ke-20, penonton hanya dapat merasakan musik di ruang tempat para pemain berkumpul secara fisik dan simultan (Thibeault, 2020). Begitu pula dengan pendidikan seni musik yang pada awalnya digunakan sebagai hal pemenuhan aspek spiritualitas, relijiusitas, dan tradisi (Karyawanto et al., 2018; Pitts, 2017).

Di dalam pembelajaran musik, pemanfaatan teknologi pembelajaran membuka peluang untuk mempelajari dan menikmati musik dengan cara yang tidak lagi mengharuskan peserta didik untuk hadir secara fisik. Teknologi pembelajaran berbasis digital memberi peserta didik memiliki akses ke lebih banyak musik daripada pembelajaran konvensional yang hampir bergantung pada pengetahuan musik yang dimiliki oleh guru (Biasutti et al., 2019; Waldron, 2013). Hal tersebut sejalan dengan pertunjukan musik saat ini yang mengedepankan kenyamanan perangkat portabel sehingga pertunjukan musik sekarang dianggap ada di mana-mana dalam kehidupan banyak orang.

Memasukkan praktik populer dengan bentuk pemanfaatan teknologi digital pada pembelajaran musik dapat membantu guru musik menghubungkan ruang kelas, teknologi, dan budaya kontemporer, sehingga menempatkan pembelajaran musik untuk terus berkembang melalui teknologi digital (Jorgensen, 2014; McPhail \& McNeill, 2019; Väkevä, 2013). Di dalam praktik tersebut, muncul performativitas yang bersifat virtual dan mengaburkan liveness dalam pertunjukan. Fenomena liveness menarik, karena performativitas jelas kemunculannya dalam praktik pembelajaran musik secara konvensional. Lebih lanjut, praktik pembelajaran musik yang memanfaatkan teknologi digital cenderung mengaburkan performativitas (Koopman, 2005).

Posisi liminal yang dialami oleh performativitas dalam praktik pembelajaran musik berbasis teknologi digital terkait dengan bergesernya aspek pedagogis (Kladder, 2020; Rantatalo \& Lindberg, 2018). Perkembangan teknologi digital yang cepat tidak diimbangi oleh kecepatan perkembangan aspek pedagogis. Di sisi lain perkembangan teknologi merupakan sebuah keniscayaan yang perlu dipertimbangkan sebagai praktik pembelajaran musik ke depannya (Partti \& Karlsen, 2010; Pendergast \& Robinson, 2020). Oleh karenanya, perlu dilakukan identifikasi dan eksplorasi terkait performativitas dan aspek pedagogis dalam praktik pembelajaran musik bagi generasi $\mathrm{Z}$.

Pembelajaran musik memiliki fleksibilitas dan kompleksitas yang membuatnya adaptif terhadap perkembangan generasi (Wright, 2019). Di dalam fokus penelitian ini, performativitas pembelajaran musik pun menjadi hal yang liminal dalam praktiknya bagi generasi $\mathrm{Z}$. Hal tersebut berkaitan dengan lingkungan belajar peserta didik Generasi $\mathrm{Z}$ yang pada dasarnya mengalami peningkatan dalam pengalaman dengan pembelajaran berbasis kreatif (Cannon, 2018; Hudson, 2020). Hal tersebut didukung dengan dominasi Internet of Thing (IoT) dalam pembelajaran. Internet dan meluasnya penggunaan gawai juga berdampak besar pada gaya belajar. Ditambah lagi, karakteristik peserta didik Generasi Z tumbuh di dunia yang selalu terhubung membuat teknologi digital memiliki peran penting dalam pembelajaran.

Praktik pembelajaran musik bagi Generasi Z tidak terbatas di ruang kelas, tetapi dapat diakses melalui YouTube dan situs pembelajaran gratis. Peserta didik Generasi Z menyukai pembelajaran mandiri yang serba cepat dan didukung dengan peluang untuk berkolaborasi sesuai kebutuhan. Mereka melihat guru sebagai fasilitator pembelajaran, yang membantu mengembangkan keterampilan yang relevan dan praktis.

Kecepatan peserta didik Generasi Z memerlukan bantuan dari guru. Lebih lanjut, kecepatan tersebut didukung dengan bagaimana aksesibilitas peserta didik Generasi Z ke lebih banyak sumber daya daripada generasi sebelumnya, namun membutuhkan bantuan dalam mempelajari cara memproses informasi 
(Cannon, 2018; Sudarsana et al., 2019). Oleh karenanya, meskipun memiliki aspek modernitas, peserta didik Generasi $\mathrm{Z}$ dan guru, memerlukan aspek konvensional yang negosiatif dalam praktik pembelajaran musik agar capaian pembelajarannya maksimal.

Berdasarkan penjabaran di atas, maka penelitian ini mencoba untuk mengidentifikasi perkembangan pembelajaran musik dalam era digital. Identifikasi juga dilakukan untuk melihat performativitas dari pembelajaran musik secara konvensional ke modern. Lebih lanjut, eksplorasi atas performativitas dan aspek pedagogis dicari dalam bingkai negosiatif. Sehingga dapat diketahui dan memperjelas terkait posisi pembelajaran musik dan fleksibilitasnya dalam pembelajaran musik secara modern bagi generasi $\mathrm{Z}$.

\section{METODE}

Penelitian ini menggunakan metode kualitatif dengan pendekatan studi kasus terhadap fenomena praktik pembelajaran musik bagi anak-anak. Penelitian ini turut melakukan kajian terhadap implikasi sosial dan pendidikan tentang bagaimana pembelajaran musik berjalan di era teknologi digital dan bagaimana pemroduksian pengetahuan melalui musik berjalan bagi generasi Z. Studi kasus dipilih sebagai pendekatan penelitian dikarenakan penelitian ini ingin mempertajam analisis dari menanyakan tentang kekhususan dan kompleksitas kasus dan aktivitas yang mengelilinginya dalam praktik pembelajaran musik Generasi Z (Denzin \& Lincoln, 2018; Lune \& Berg, 2017). Dengan memahami keunikan kasus terkait pedagogis pembelajaran musik Generasi Z, peneliti dapat mengekstrapolasi informasi yang dapat mempengaruhi sudut pandang masyarakat pendidikan dalam melihat fenomena. Jika metode kualitatif diadaptasi untuk memberikan wawasan untuk memahami bagaimana aspek pedagogis terungkap sebagai pijakan awal penelitian (Denzin \& Lincoln, 2018), maka studi kasus berpotensi untuk menginformasikan praktik pembelajaran musik Generasi Z secara eksploratif (Leavy, 2017; Lune \& Berg, 2017).

Sumber data penelitian ini adalah 100 guru musik yang bekerja di lembaga formal, yang memiliki batasan spasial di Surabaya dan Sidoarjo, Jawa Timur. Dua lokasi tersebut dipilih atas pertimbangan keterjangkauan penelitian, di mana mempermudah peneliti dalam mencari informan.
Penelitian dilakukan pada bulan April 2020 hingga Januari 2021. Penelitian diawali dengan memberikan kuesioner terkait praktik pembelajaran musik bagi Generasi Z. Posisi kuesioner bukan menjadi konsep primer dalam pengumpulan data, namun sesuai dengan prinsip pencarian data penelitian kualitatif yang memperbolehkan untuk meminjam konsep kuantitatif dalam wujud kuesioner untuk mempermudah dan mempertajam analisis kualitatif yang dilakukan (Mills, 2019; Shkedi, 2019). Selain itu, data diperoleh dari melakukan wawancara terhadap 5 guru musik Generasi Z. Informan dipilih berdasarkan prinsip purposive (Mills, 2019), dengan kriteria (1) sarjana pembelajaran musik, (2) telah mengajar 3 tahun, (3) usia informan berada di bawah 35 tahun. Pertimbangan tersebut ditentukan agar data yang diperoleh tajam, aktual, dan wawancara yang dilakukan dapat berkembang sehingga data yang dikumpulkan semakin variatif dan mendukung penelitian.

Analisis data menggunakan model interaktif milik Miles dan Huberman, di mana penelitian diposisikan dalam setting natural sehingga analisis dapat dilakukan bersamaan dengan pengumpulan data (Miles et al., 2018). Lebih lanjut, perspektif yang digunakan dalam penelitian merujuk pada konsep tentang aspek musikal anak-anak yang dipopulerkan oleh Schu-Fang Lin. Konsepsi dari Schu-Fang Lin (2019) pada akhirnya didukung dengan sudut pandang dari Helena Gaunt (2016) tentang pedagogis pembelajaran musik Abad 21. Kedua sudut pandang tersebut menjadi pijakan utama dalam analisis data, didukung dengan literatur lain yang mampu mewacanakan penelitian terkait praktik pembelajaran musik Generasi Z.

\section{HASIL DAN PEMBAHASAN \\ Hasil}

Pembelajaran musik di era Generasi Z pada dasarnya mempertimbangkan aspek fleksibilitas. Fleksibilitas terletak pada aspek media dan cara penyampaiannya. Guru musik para Generasi Z mulai beradaptasi terhadap perkembangan teknologi.

Pemanfaatan teknologi yang dilakukan oleh guru musik tidak hanya menyasar pada guru dengan usia yang relatif muda dan bersifat fresh graduate. Guru yang memiliki lebih dari 7 tahun masa bakti, tetap mampu beradaptasi dengan memanfaatkan teknologi sebagai media pembelajaran musiknya (Tabel 1). Meski demikian, guru dengan masa bakti 3,6-7 tahun 
memiliki varietas yang beragam dibandingkan dengan yang lainnya (Tabel 1).

Tabel 1. Pemanfaatan guru terhadap teknologi dalam pembelajaran musik

\begin{tabular}{|c|c|c|c|c|}
\hline $\begin{array}{l}\text { Jumlah } \\
\text { rentang } \\
\text { rerata }\end{array}$ & $\begin{array}{c}\text { Rerata pengalaman } \\
\text { mengajar (dalam } \\
\text { tahun)* }\end{array}$ & $\begin{array}{c}\text { Memahami } \\
\text { teknologi } \\
\text { pembelajaran** }\end{array}$ & $\begin{array}{c}\text { Memanfaatkan } \\
\text { teknologi dalam } \\
\text { pembelajaran } \\
\text { musik*** }\end{array}$ & $\begin{array}{l}\text { Pemanfaatan teknologi (dari } \\
\text { yang paling sering) } * * * *\end{array}$ \\
\hline $1-20$ & $1-3,5\left(\sum=15\right)$ & $\sqrt{ }$ & $\sqrt{ }$ & $\begin{array}{c}\text { Browsing, YouTube, platform } \\
\text { belajar lainnya }\end{array}$ \\
\hline $21-40$ & $>7\left(\sum=23\right)$ & $\sqrt{ }$ & $\sqrt{ }$ & $\begin{array}{c}\text { YouTube, browsing, platform } \\
\text { belajar lainnya }\end{array}$ \\
\hline $41-60$ & $3,6-7\left(\sum=58\right)$ & $\sqrt{ }$ & $\sqrt{ }$ & $\begin{array}{l}\text { YouTube, grup WhatsApp, } \\
\text { browsing internet, }\end{array}$ \\
\hline$\sum=100$ & $\sum=100$ & & & \\
\hline \multicolumn{5}{|c|}{$\begin{array}{l}\text { Keterangan: } \\
\text { *data disederhanakan } \\
* * \text { diambil dari rerata terbanyak } \\
\text { *** diambil dari rerata terbanyak } \\
* * * * \text { diambil dari rerata terbanyak } \\
\text { Data dalam tabel diperoleh dari coding terhadap kuesioner yang dibagikan pada bulan April } 2020 \text { hingga Januari } 2021 \\
\text { kepada } 100 \text { guru musik di Surabaya dan Sidoarjo, Jawa Timur. }\end{array}$} \\
\hline
\end{tabular}

Masalah utama pedagogi dalam musik saat ini adalah tentang kemampuan guru memahami sifat proses inovasi dalam pendidikan. Masalah seperti permasalahan belajar, generalisasi, dan penyebaran pengalaman pedagogis memengaruhi bagaimana konsepsi guru tentang perkembangan teknologi. Lebih lanjut, guru kesulitan menegosiasikan dan memosisikan ulang letak pdagogis dan performativitas sebagai unsur yang saling berhubungan dalam pembelajaran musik Generasi Z.

"Saya dari saat kuliah memang suka mengutak-atik teknologi. Dulu sebagian besar teknologi editing saya unduh dari smartphone karena belum punya modal. Dulu pikirnya saya senang-senang saja, namun sebenarnya agak tidak menyangka kalau sekarang bisa digunakan untuk mengajar" (Wawancara A, guru musik, 27 tahun).

Sebagai seorang guru muda, A memberikan penjelasan terkait muasalnya mengenal teknologi dalam pembelajaran. Mengacu pada produksi arena kultural, maka A mendapatkan modal kultural dari tempat A mengenyam pendidikan guru musik. Modal kultural memiliki faktor yang menentukan dalam eksistensi individu dalam masyarakat, di mana modal kultural turut meningkatkan kemampuan adaptif dari individu (Bourdieu, 1999; M. B. T. Sampurno et al., 2020). Berbeda dengan B, yang menganggap pembelajaran musik saat ini telah menjadi entertainment, bukan sekadar tentang pedagogis saja.

"Saya sudah menggunakan YouTube sebagai wahana pertunjukan siswa. Alasannya karena biaya, di mana sekolah tidak memiliki biaya untuk menghelat pertunjukan live. Maka dari itu saya inisiatif untuk memanfaatkan YouTube untuk pertunjukan virtual" (Wawancara B, guru musik, 28 tahun).

Argumentasi B tentang hal-hal material menjadi masalah utama dalam perkembangan pendidikan seni di Indonesia. Tidak hanya terjadi dalam musik, rupa dan tari pun mengalami hal yang sama. Hal tersebut diamini oleh C, yang awalnya memiliki kesulitan dalam penyajian keterampilan peserta didik ke masyarakat.

"Saya akhirnya menggunakan media sosial. Kebetulan saya mengajar seni budaya, jadinya semua seni saya ajarkan. Prinsip awal saya adalah pameran, pentas seni, begitu. Tapi karena seni menjadi anak tiri di sekolah, dananya tidak ada. Itu membuat saya pasrah dan mencoba berpikir dan ternyata bisa memanfaatkan media sosial saja meskipun saya buat temporer. Biar kesan livenessnya tetap ada" (Wawancara C, guru seni budaya, 30 tahun). 
Pembelajaran musik dengan memanfaatkan teknologi juga dimanfaatkan oleh $\mathrm{D}$, di mana ia mengajar dengan tidak menggunakan referensi cetak (hardcopy). D beranggapan bahwa dalam mengajar generasi saat ini diperlukan kerjasama dengan teknologi, terutama gawai yang seharihari digunakan. Oleh karenanya, D benar-benar memanfaatkan teknologi dalam pembelajaran musik yang diampunya.

"Saya kebetulan punya adik ya seumuran anak SMP kelas 1. Ternyata sama saja karakternya. Mereka tidak bisa lepas dari smartphone. Maka dari itu, saya membuat sebuah gebrakan, yaitu saya tidak menggunakan buku paket, tapi referensi yang saya gunakan itu benar-benar memanfaatkan internet. Siswa saya instruksikan untuk browsing, lalu diskusi. Itu saya rasa lebih efektif" (Wawancara D, guru musik, 28 tahun).

Keberadaan teknologi direspons baik oleh guruguru musik dengan menggunakannya sebagai salah satu elemen penting dalam pembelajaran (Tabel 1).

"Saya merasa teknologi itu seperti dua sisi mata uang. Mereka satu, mendukung pembelajaran. Tapi di sisi lain mereka seperti bertentangan. Maka dari itu guru harus pintar-pintar jangan sampai terjebak dan terlena pada kenyamanan teknologi” (Wawancara E, guru seni budaya, 32 tahun)

Namun, di sisi lain, hampir semua guru berpendapat bahwa perlu adanya kontrol dari guru sendiri terhadap keberlangsungan pembelajaran musik berbasis teknologi. Hal tersebut dilakukan untuk tetap mengutamakan aspek pedagogis dan menghindari bias ketercapaian. Oleh karenanya, negosiasi pembelajaran perlu dilakukan.

Pembahasan

Salah satu contoh menegosiasikan ulang performativitas dan pedagogis adalah praktik musikal dari penggabungan pertunjukan dan teknologi. Ide mendasar dalam penggabungan teknologi baru dalam pembelajaran musik adalah dalam memanfaatkan pengalaman pembelajaran konvensional sebagai titik awal untuk menciptakan ruang baru yang akan memudahkan penggunaan teknologi secara kreatif. Jelaslah bahwa teknologi harus diintegrasikan dalam praktik yang dilakukan oleh para guru musik para Generasi Z setiap hari dalam pembelajaran mereka. Integrasi ini memungkinkan munculnya eksplorasi dan eksperimen dengan musik, dan menjadi elemen yang berdialog dengan praktik dalam memperkaya kemampuan musikal peserta didik Generasi Z.

Perkembangan pembelajaran musik saat ini telah mencakup tidak hanya dalam media penyampaiannya, namun juga terkait luaran dan/atau capaiannya. Pembelajaran musik secara konvensional mengacu pada konsepsi pendidikan seni untuk anak dari Ki Hadjar Dewantara yang menggarisbawahi tujuannya adalah untuk melatih cipta, rasa, dan karsa anak sebagai peserta didik (Ki Hadjar Dewantara, 2004). Konsepsi tersebut lestari hingga periode 2000an, dan mulai pudar dengan kontestasi capaian pembelajaran musik melalui lomba (Walby et al., 2017). Identifikasi pergeseran pembelajaran musik pada periode 2000an tersebut pada akhirnya menjadi pijakan penting. Hal tersebut dikarenakan munculnya teknologi dalam pembelajaran membuat kontestasi secara konvensional tersamarkan. Melalui internet dengan media sosialnya (YouTube, Instagram, TikTok) kontestasi capaian pembelajaran musik justru memasuki ranah kreatif (Cayari, 2018; Richert et al., 2011). Tentunya hal ini menjadi hal yang positif, karena negosiasi akan terjalin antara guru dan peserta didik untuk bersamasama berkarya dan mencari apresiasi virtual melalui media sosial.

Diawali dari perubahan paradigma tentang media sosial dari sekadar eksistensial ke dalam sudut pandang pedagogis, maka performativitas pun turut bergeser (Gaunt \& Westerlund, 2016). Pembelajaran musik yang memiliki partikel-partikel pendukungnya saat ini melebur menjadi satu kesatuan dalam bingkai aspek musikal (Gambar 1). Penyatuan tersebut tidak serta-merta menghilangkan esensi pedagogis yang ada dalam pembelajaran musik, namun lebih pada transformasi ke dalam satu bentuk pertunjukan yang sarat performativitas (Gambar 1).

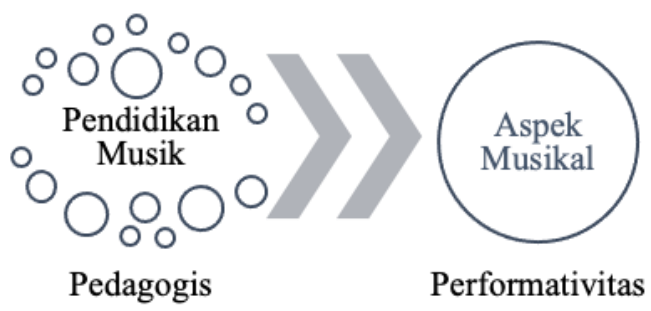

Gambar 1. Skema transformasi pedagogis dan performativitas 
Untuk memfasilitasi implementasi transformasi pedagogis dan teknologi dalam tahap pembuatannya, serangkaian skenario pembelajaran pada dasarnya telah dirancang. Skenario pertama dalam pembelajaran musik Generasi $\mathrm{Z}$ menyajikan dua situasi yang liminal (Lin, 2019). Kelas dibagi menjadi kelompokkelompok kecil yang terdiri dari lima atau enam peserta didik. Setiap kelompok dapat menggunakan perangkat teknologi: smartphone dan tablet. Dikombinasikan dengan objek lain dan instrumen tradisional, yang dapat direkam dan diubah secara real time menggunakan perangkat lunak. Melalui sistem pembelajaran mengacu pada pedagogis komunal yang bersifat menyeluruh, setiap kelompok dapat melakukan aktivitas yang berbeda dalam kemungkinan pemanfaatan teknologi. Kegiatan di kelas harus difokuskan pada perolehan dan manipulasi suara di tingkat dasar, untuk membangun pengetahuan dasar yang baik. Kegiatan ini melebar dalam ranah interdisiplinaritas dalam kegiatan mencakup pembuatan gambar latar musikal, baik statis atau dinamis dan pembuatan perpustakaan sumber daya yang nantinya akan digunakan untuk membuat karya audio-visual (Gaunt \& Westerlund, 2016; Lin, 2019).

Situasi kedua, pembelajaran musik bisa terfokus pada improvisasi musik. Tujuan dari kegiatan ini adalah untuk mengkonsolidasikan pengalaman estetik melalui mendengarkan secara kolektif dan mendorong diskusi yang akan memberikan analisis rinci tentang proses suara yang berasal dari kegiatan tersebut (Gaunt \& Westerlund, 2016; Lin, 2019). Dalam fase ini, kumpulan ide, bukan kumpulan suara, diproduksi. Prinsipnya adalah mengawali dengan karya, diproses dengan pengolahan daya kritisisme pemikiran anak Generasi Z, dan pada akhirnya hasil diskusi digunakan untuk membuat karya. Melalui dua opsi tawaran tersebut, pembelajaran musik Generasi Z memberikan dua hal yang negosiatif.

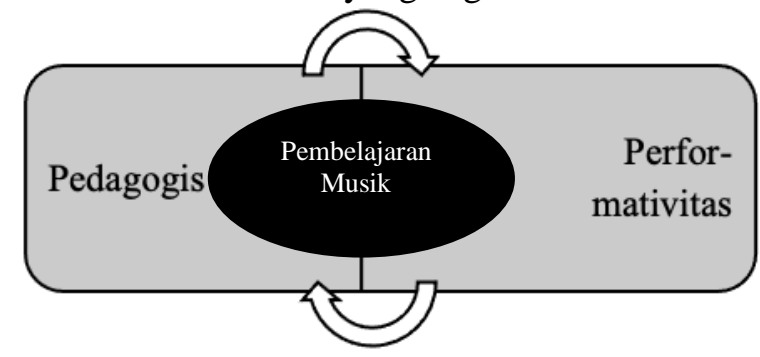

Gambar 2. Negosiasi performativitas pedagogis dalam pembelajaran musik
Negosiasi performativitas dan pedagogis dalam teknologi pembelajaran musik yang berkembang membutuhkan pendekatan yang berbeda. Secara global, individu dari segala usia telah menggunakan teknologi yang mendorong keterbukaan dan partisipasi pendidikan, sosial, budaya, dan ekonomi secara inheren. Faktanya, popularitas jejaring sosial telah meningkat pesat selama beberapa tahun terakhir (CastañoMuñoz et al., 2014; Colman, 2018). Di sisi lain, kekhawatiran tentang aspek-aspek musik dasar untuk tersamarkan dan saling tumpang-tindih dengan persoalan entertainment menjadi nyata adanya. Misalnya terkait orkestrasi dan aransemen musik. Orkestrasi dan aransemen memberikan pengalaman dalam pembelajaran musik dengan mengolah bentuk ide kreatif dapat diperoleh melalui imajinasi seorang arranger untuk menyusun konsep awal dalam sebuah aransemen musik (Karyawanto, 2018). Ketika hal tersebut dilakukan dengan pemanfaatan teknologi, esensi dasar menjadi tersamarkan (Abels, 2019; Powell et al., 2017).

Kekhawatiran juga muncul ketika membicarakan aspek tradisi dalam pembelajaran musik bagi Generasi Z. Isu terkait tradisi memang telah menjadi keniscayaan yang menarik untuk dipelajari. Generasi Z memerlukan pemahaman tentang musik tradisi agar memberikan pengalaman estetik berbasis tradisi dan lokalitas, sehingga mampu memiliki pengetahuan empiris tentang musik tradisi (Capwell, 2010; Karyawanto et al., 2018; Karyawanto \& Noordiana, 2018; Katromi, 2017; Vasil et al., 2019). Dengan melakukan negosiasi terhadap performativitas musikal dan pedagogis dalam pembelajaran maka semua aspek penting dari musik tradisi akan tersampaikan.

Ditinjau dari sudut pandang pembelajaran musik yang terintegrasi dengan ekonomi kreatif, negosiasi performativitas dan pedagogis mengambil langkah penting. Sebagai hasil dari revolusi industri di abad 19, pada dasarnya pendidikan berubah dari magang menjadi sekolah universal (Choi \& Piro, 2009; Jahnke et al., 2017; Maney, 1999). Di era IoT ini, sebagian besar yang dipelajari peserta didik terjadi di luar sekolah. Sekolah secara universal membuat masyarakat mengidentifikasi pembelajaran melalui lembaga sekolah, namun sekarang identifikasi keduanya terurai.

Di dalam masyarakat sekitar, individu belajar dengan bantuan teknologi baru dan 
memercayai bahwa pendidikan meletakkan fondasi untuk era digital saat ini di mana ada peningkatan penggunaan dan ketergantungan pada teknologi digital (Irwin et al., 2012; Kim et al., 2002). Hal ini memiliki efek yang mendalam pada cara masyarakat, terutama Generasi $\mathrm{Z}$ dalam mengakses pengetahuan, berinteraksi, berkreasi, berkolaborasi, dan belajar. Negosiasi perlu terjadi untuk melakukan filtrasi melalui pengaturan pendidikan jika pembelajaran dan pengajaran terjadi dengan cara kontemporer. Teknologi dan guru beresonansi dengan peserta didik Generasi $\mathrm{Z}$ karena itulah cara mereka berinteraksi dan terlibat dalam konteks kehidupan nyata (Lin, 2019).

Di dalam menangani pedagogi pendidikan, penting untuk memosisikan teknologi mengubah epistemologi dari apa yang mungkin atau mungkin tidak diajarkan di sekolah (Ghavifekr \& Rosdy, 2015; T. Sampurno, 2015; Taylor \& Carpenter, 2016). Untuk memahami perubahan pedagogis yang diperlukan, pertama-tama perlu dilakukan evaluasi terhadap implikasi teknologi tersebut, tantangan dan manfaatnya bagi pengajaran dan pembelajaran musik. Di sisi lain, sangat penting untuk mengakui bahwa guru membutuhkan pengembangan profesional yang sesuai dan dukungan untuk mengubah pedagogis mereka yang sesuai dalam lingkungan digital yang berkembang pesat.

\section{KESIMPULAN}

Negosiasi performativitas dan pedagogis pada akhirnya menuju pada model pembelajaran multidimensi. Pembelajaran multidimensi menyoroti keuntungan dalam merangkul teknologi untuk pembelajaran musik bagi Generasi Z. Kombinasi pengajaran tradisional dan tatap muka dengan pembelajaran berbasis teknologi memiliki keniscayaan akan menghasilkan konsep yang diterima karena sesuai dengan karakteristik peserta didik Generasi Z.

Secara pedagogis, pembelajaran multidimensi bertujuan untuk memasukkan aspek-aspek dari pengalaman pembelajaran kelas tatap muka dengan pengalaman pembelajaran berbasis teknologi. Hal tersebut memungkinkan terjadinya peningkatan ukuran hasil belajar baik dari pedagogis maupun performativitas musikal. Selain itu, membuka kesempatan bagi peserta didik Generasi $\mathrm{Z}$ untuk mempraktikkan keterampilan teknologi dalam menavigasi materi musik dan konten digital mereka sendiri.

Negosiasi pedagogis dan performativitas dalam pembelajaran musik bagi Generasi $\mathrm{Z}$ menjadi cerminan masyarakat saat ini yang beraneka ragam. Oleh karenanya harus mencakup integrasi tak terbatas dari teknologi interaktif. Negosiasi tersebut bekerja secara bersamaan, memperkenalkan gagasan tentang perspektif holistik, praktik pembelajaran, dan performativitas untuk memberikan wacana baru terhadap perkembangan pembelajaran musik bagi Generasi Z.

\section{DAFTAR PUSTAKA}

Abels, B. (2019). A Poetics of Dwelling with Music and Dance: Le Hip-Hop As Homing Practice. World of Music, 8(1), 49-64.

Biasutti, M., Frate, S., \& Concina, E. (2019). Music teachers' professional development: assessing a three-year collaborative online course. Music Education Research, 21(1), 116-133. https://doi.org/10.1080/14613808.2018.15 34818

Bourdieu, P. (1999). Language and Symbolic Power. Harvard University Press.

Cannon, M. (2018). Digital Media in Education: Teaching, Learning and Literacy Practices with Young Learners. The Palgrave Macmillan. https://doi.org/10.1007/978-3-319-783048

Capwell, C. (2010). Contemporary Manifestations of Yemeni-Derived Song and Dance in Indonesia. Yearbook for Traditional Music, 27(1995), 76-89.

Castaño-Muñoz, J., Duart, J. M., \& SanchoVinuesa, T. (2014). The Internet in faceto-face higher education: Can interactive learning improve academic achievement? British Journal of Educational Technology, 45(1), 149-159. https://doi.org/10.1111/bjet.12007

Cayari, C. (2018). Connecting music education and virtual performance practices from YouTube. Music Education Research, 20(3), 360-376. https://doi.org/10.1080/14613808.2017.13 83374

Choi, H., \& Piro, J. M. (2009). Expanding arts education in a digital age. Arts Education Policy Review, 110(3), 27-34. https://doi.org/10.3200/AEPR.110.3.27-34 Colman, A. (2018). Net.art and Net.pedagogy: 
Introducing Internet Art to the Digital Art Curriculum. Studies in Art Education, 46(Technology Issue), 61-73.

Denzin, N. K., \& Lincoln, Y. S. (Eds.). (2018). The SAGE Handbook of Qualitative Research (Fifth Edit). Sage Publications. https://doi.org/10.1007/s11229-017-1319$\mathrm{X}$

Gaunt, H., \& Westerlund, H. (Eds.). (2016). Collaborative Learning in Higher Music Education. Routledge.

Ghavifekr, S., \& Rosdy, W. A. W. (2015). Teaching and learning with technology: Effectiveness of ICT integration in schools. International Journal of Research in Education and Science, 1(2), 175-191. https://doi.org/10.21890/ijres.23596

Hudson, T. D. (2020). Conversation as an Education Medium for the Age of Distraction - the 'Art of Range' Podcast. Rangelands, 42(1), 9-16. https://doi.org/10.1016/j.rala.2020.01.005

Irwin, C., Ball, L., Desbrow, B., \& Leveritt, M. (2012). Students' perceptions of using Facebook as an interactive learning resource at university. Australasian Journal of Educational Technology, 28(7), 1221-1232.

Jahnke, I., Haertel, T., \& Wildt, J. (2017). Teachers' conceptions of student creativity in higher education. Innovations in Education and Teaching International, 54(1), 87-95. https://doi.org/10.1080/14703297.2015.10 88396

Jorgensen, E. R. (2014). Values and philosophizing about music education. Philosophy of Music Education Review, 22(1), 5-21.

Karyawanto, H. Y. (2018). Bentuk Lagu Dan Ambitus Nada Pada Orkestrasi Mars Unesa. Virtuoso: Jurnal Pengkajian Dan Penciptaan Musik, $1(1), \quad 8$. https://doi.org/10.26740/vt.v1n1.p8-14

Karyawanto, H. Y., \& Noordiana. (2018). Sariswara Method as the Basis of Art Lesson in Tamansiswa. 2nd Social Sciences, Humanities, and Education Conference (SoSHEC 2018) Sariswara, 222(SoSHEC), $165-170$. https://doi.org/10.2991/soshec-18.2018.36

Karyawanto, H. Y., Sarjoko, M., \& Murbiyantoro, H. (2018). Musik Oklek Sebagai Sarana Ritual Masyarakat.
Journal of Art, Design, Art Education and Culture Studies (JADECS), 3(1).

Katromi, M. J. (2017). "Traditional Music Weeps" and other Themes in the Discourse on Music, Dance and Theatre of Indonesia, Malaysia and Thailand. Journal of Southeast Asian Studies, 26(2), 366-400.

Ki Hadjar Dewantara. (2004). Karya Ki Hadjar Dewantara Bagian I: Pendidikan. Majelis Luhur Persatuan Taman Siswa.

Kim, B., Williams, R., \& Dattilo, J. (2002). Students' perception of interactive learning modules. Journal of Research on Technology in Education, 34(4), 453-473. https://doi.org/10.1080/15391523.2002.10 782361

King, A., Prior, H., \& Waddington-Jones, C. (2019). Exploring teachers' and pupils' behaviour in online and face-to-face instrumental lessons. Music Education Research, 21(2), 197-209. https://doi.org/10.1080/14613808.2019.15 85791

Kladder, J. (2020). Re-envisioning music teacher education: An investigation into curricular change at two undergraduate music education programs in the U.S. Arts Education Policy Review, 121(4), 141159.

https://doi.org/10.1080/10632913.2019.16 70311

Koopman, C. (2005). Music education, performativity and aestheticization. Educational Philosophy and Theory, 37(1),

119-131.

https://doi.org/10.1111/j.1469-

5812.2005.00102.x

Leavy, P. (2017). Research Design: Quantitative, Qualitative, Mixed Methods, Arts-Based, and Community-Based Participatory Research Approaches. The Guilford Press.

Lin, S.-F. (2019). Discovering Young Children's Musical Creativity in Their Everyday Life. In Y. Tsubonou, A.-G. Tan, \& M. Oie (Eds.), Creativity in Music Education (pp. 59-72). Springer.

Lune, H., \& Berg, B. L. (2017). Qualitative Research Methods for the Social Sciences (Ninth edit). Pearson.

Maney, J. K. (1999). The Role of Technology in Education. Handbook of Educational Policy, January, 387-415. 
https://doi.org/10.1016/b978-0121746988/50043-6

McPhail, G., \& McNeill, J. (2019). One direction: a future for secondary school music education? Music Education Research, 21(4), 359-370. https://doi.org/10.1080/14613808.2019.16 05345

Miles, M. B., Huberman, A. M., \& Saldana, J. (2018). Qualitative Data Analysis: A Methods Sourcebook (4th ed.). Sage Publications.

Mills, K. A. (2019). Big Data for Qualitative Research. In Routledge Focus. Routledge. https://doi.org/10.4324/9780429056413

Partti, H., \& Karlsen, S. (2010). Reconceptualising musical learning: New media, identity and community in music education. Music Education Research, 12(4), 369-382. https://doi.org/10.1080/14613808.2010.51 9381

Pendergast, S., \& Robinson, N. R. (2020). Secondary Students' Preferences for Various Learning Conditions and Music Courses: A Comparison of School Music, Out-of-School Music, and Nonmusic Participants. Journal of Research in Music Education, 68(3), 264-285. https://doi.org/10.1177/002242942093182 6

Pitts, S. E. (2017). What is music education for? Understanding and fostering routes into lifelong musical engagement. Music Education Research, 19(2), 160-168. https://doi.org/10.1080/14613808.2016.11 66196

Powell, B., Smith, G. D., \& D'Amore, A. (2017). Challenging symbolic violence and hegemony in music education through contemporary pedagogical approaches. Education 3-13, 45(6), 734-743. https://doi.org/10.1080/03004279.2017.13 47129

Rantatalo, O., \& Lindberg, O. (2018). Liminal practice and reflection in professional education: police education and medical education. Studies in Continuing Education, 40(3), 351-366. https://doi.org/10.1080/0158037X.2018.1 447918

Richert, R. A., Robb, M. B., Smith, E. I., Development, S. C., Healthy, R., January, C., Richert, R. A., Robb, M. B., \& Smith, E. I. (2011). Media as Social Partners: The
Social Nature of Young Children's Learning From Screen Media. Child Development, $\quad$ 82(1), 82-95. https://doi.org/10.1111/j.14678624.2010.01542.x

Sampurno, M. B. T., Prabandari, Y. S., \& Marianto, M. D. (2020). Theoretical Exploration of Art Therapy and Education for Autistic Children. International Journal of Indonesian Education and Teaching (IJIET), 4(2). https://doi.org/10.24071/ijiet.2020.040209

Sampurno, T. (2015). Seni, Melukis, dan Anak Autis: Penanganan dan Pengembangan melalui Seni dan Cara Mengevaluasi Karya Anak Autis. Psikosain.

Shkedi, A. (2019). Introduction to Data Analysis in Qualitative Research. Springer International Publishing.

Sudarsana, I. K., Nakayanti, A. R., Sapta, A., Haimah, Satria, E., Saddhono, K., Achmad Daengs, G. S., Putut, E., Helda, T., \& Mursalin, M. (2019). Technology Application in Education and Learning Process. Journal of Physics: Conference Series, 1363(1). https://doi.org/10.1088/17426596/1363/1/012061

Taylor, P. G., \& Carpenter, B. S. (2016). Mediating Art Education: Digital Kids, Art , and Technology. Visual Arts Research, 33(2), 84-95.

Thibeault, M. D. (2020). Dewey's Musical Allergy and the Philosophy of Music Education. Journal of Research in Music Education, 68(1), 31-52. https://doi.org/10.1177/002242941989679 2

Väkevä, L. (2013). Four pieces on comparative philosophy of music education. Philosophy of Music Education Review, 21(1), 5-7.

Vasil, M., Weiss, L., \& Powell, B. (2019). Popular Music Pedagogies: An Approach to Teaching 21st-Century Skills. Journal of Music Teacher Education, 28(3), 8595.

https://doi.org/10.1177/105708371881445 4

Walby, S., Olive, P., Towers, J., Francis, B., Strid, S., Krizsán, A., Lombardo, E., MayChahal, C., Franzway, S., Sugarman, D., Agarwal, B., \& Armstrong, J. (2017). Culture, media and education. Stopping Rape, 191-210. 
https://doi.org/10.2307/j.ctt1t89hb4.11

Waldron, J. (2013). User-generated content, YouTube and participatory culture on the Web: Music learning and teaching in two contrasting online communities. Music Education Research, 15(3), 257-274. https://doi.org/10.1080/14613808.2013.77 2131

Waldron, J., Mantie, R., Partti, H., \& Tobias, E. S. (2018). A brave new world: theory to practice in participatory culture and music learning and teaching. Music Education Research, 20(3), 289-304. https://doi.org/10.1080/14613808.2017.13 39027

Wright, R. (2019). Envisioning real Utopias in music education: prospects, possibilities and impediments. Music Education Research, 21(3), 217-227. https://doi.org/10.1080/14613808.2018.14 84439 